\title{
Changes in brain activation related to visuo-spatial memory after real-time fMRI neurofeedback training in healthy elderly and Alzheimer's disease
}

Citation for published version (APA):

Hohenfeld, C., Kuhn, H., Müller, C., Nellessen, N., Ketteler, S., Heinecke, A., Goebel, R., Shah, N. J., Schulz, J. B., Reske, M., \& Reetz, K. (2020). Changes in brain activation related to visuo-spatial memory after real-time fMRI neurofeedback training in healthy elderly and Alzheimer's disease. Behavioural Brain Research, 381, [112435]. https://doi.org/10.1016/j.bbr.2019.112435

Document status and date:

Published: 02/03/2020

DOI:

10.1016/j.bbr.2019.112435

Document Version:

Publisher's PDF, also known as Version of record

\section{Document license:}

Taverne

Please check the document version of this publication:

- A submitted manuscript is the version of the article upon submission and before peer-review. There can be important differences between the submitted version and the official published version of record.

People interested in the research are advised to contact the author for the final version of the publication, or visit the DOI to the publisher's website.

- The final author version and the galley proof are versions of the publication after peer review.

- The final published version features the final layout of the paper including the volume, issue and page numbers.

Link to publication

\footnotetext{
General rights rights.

- You may freely distribute the URL identifying the publication in the public portal. please follow below link for the End User Agreement:

www.umlib.nl/taverne-license

Take down policy

If you believe that this document breaches copyright please contact us at:

repository@maastrichtuniversity.nl

providing details and we will investigate your claim.
}

Copyright and moral rights for the publications made accessible in the public portal are retained by the authors and/or other copyright owners and it is a condition of accessing publications that users recognise and abide by the legal requirements associated with these

- Users may download and print one copy of any publication from the public portal for the purpose of private study or research.

- You may not further distribute the material or use it for any profit-making activity or commercial gain

If the publication is distributed under the terms of Article 25fa of the Dutch Copyright Act, indicated by the "Taverne" license above, 
Research report

\section{Changes in brain activation related to visuo-spatial memory after real-time fMRI neurofeedback training in healthy elderly and Alzheimer's disease}

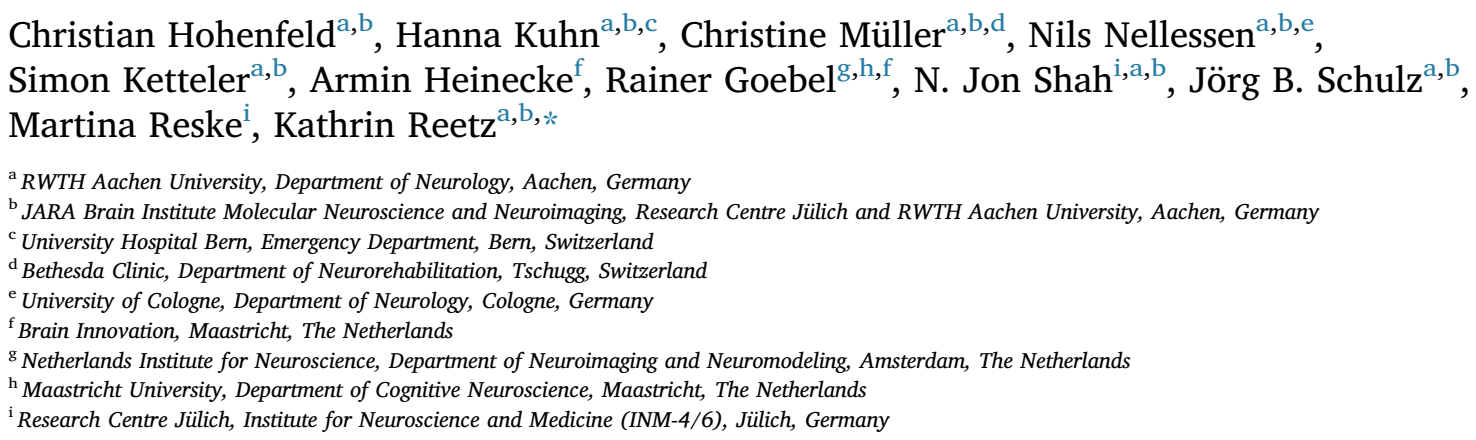

\section{A R T I C L E I N F O}

\section{Keywords:}

Ageing

Alzheimer's disease

Neurofeedback

Parahippocampus

Visuo-spatial memory

\begin{abstract}
A B S T R A C T
Cognitive decline is a symptom of healthy ageing and Alzheimer's disease. We examined the effect of real-time fMRI based neurofeedback training on visuo-spatial memory and its associated neuronal response.

Twelve healthy subjects and nine patients of prodromal Alzheimer's disease were included. The examination spanned five days (T1-T5): T1 contained a neuropsychological pre-test, the encoding of an itinerary and a fMRIbased task related that itinerary. T2-T4 hosted the real-time fMRI neurofeedback training of the parahippocampal gyrus and on T5 a post-test session including encoding of another itinerary and a subsequent fMRIbased task were done. Scores from neuropsychological tests, brain activation and task performance during the fMRI-paradigm were compared between pre and post-test as well as between healthy controls and patients.

Behavioural performance in the fMRI-task remained unchanged, while cognitive testing showed improvements in visuo-spatial memory performance. Both groups displayed task-relevant brain activation, which decreased in the right precentral gyrus and left occipital lobe from pre to post-test in controls, but increased in the right occipital lobe, middle frontal gyrus and left frontal lobe in the patient group.

While results suggest that the training has affected brain activation differently between controls and patients, there are no pointers towards a behavioural manifestation of these changes. Future research is required on the effects that can be induced using real-time fMRI based neurofeedback training and the required training duration to elicit broad and lasting effects.
\end{abstract}

\section{Introduction}

Alzheimer's disease (AD) is a major worldwide public health issue. With increasing life expectancy, the number of people affected is rising, but despite extensive research there is no cure yet $[1,2]$.

The main symptom of $\mathrm{AD}$ is progressive cognitive decline caused by widespread neurodegeneration. While eventually all domains of cognition become affected, the first domain to show impaired functioning is usually visuo-spatial memory - a subdomain of episodic memory. This cognitive domain has been associated with the parahippocampal gyrus $[3,4]$. As this region is among the earliest affected by the progressive neurodegeneration of $\mathrm{AD}$ [5], the early impairment of visuospatial memory is straightforward. Impaired visuo-spatial memory affects daily living tremendously, as the ability to navigate both familiar and novel environments is critical for independent living. Decline of visuo-spatial memory is also a concern in healthy ageing, albeit to a much smaller extent than in AD [6-8].

Throughout the past decade research using real-time functional MRI (rtfMRI) neurofeedback has demonstrated that both cognitive abilities of various domains and symptoms of diseases with central nervous

\footnotetext{
* Corresponding author at: University Hospital Aachen, Department of Neurology, Pauwelsstraße 30, 52074 Aachen, Germany.

E-mail address: kreetz@ukaachen.de (K. Reetz).
} 
involvement can be improved using this method [9-11]. While open questions remain and targeted clinical trials for routine application of rtfMRI in clinical settings have not been carried out yet, results from these studies are promising and warrant further research into this field.

Especially considering results from studies targeting memory it seems like various domains of memory can be trained and cognitive performance improved using rtfMRI training paradigms [12,13]. Furthermore, studies implementing rtfMRI paradigms targeting the parahippocampal gyrus have demonstrated that this region is indeed a feasible target for those paradigms and its activation can be voluntarily modulated [13].

Based on preceding results, we here aimed to implement a proof-ofconcept study that investigated brain activation in a visuo-spatial navigation task during fMRI that was embedded into a rtfMRI neurofeedback training paradigm [14]. The present work focuses on the fMRI task before and after the training, while the previously published manuscript addressed the rtfMRI training itself as well as changes in neuropsychological tests. In addition to brain changes we were also interested in potential behavioural changes manifesting in the fMRI task after the training. Of course, changes in neuropsychological performance were also of interest in the context of the present setting, but these changes were already reported in-depth in the literature [14].

We hypothesised that (1) both groups would elicit memory-related activation before the training, but healthy elderly more extensively than patients; (2) task performance would show ceiling effects in healthy subjects but be considerably worse in patients and (3) brain activation would change after rtfMRI neurofeedback training and additionally in patients task performance would be improved.

\section{Methods}

\subsection{Subjects}

In total, 26 subjects completed the paradigm, split into a group of healthy controls and a group of patients of prodromal Alzheimer's disease $[15,16]$. Four healthy subjects and one patient had to be excluded from the analysis due to technical problems or excessive motion during scanning, leading to a final sample of 21 subjects. The sample included here is a subsample of the sample included in the previous paper focusing on the training [14].

General inclusion criteria were absence of metallic implants for MRI safety, right-handedness as assessed by a simplified version of the Edinburgh Handedness Inventory [17] no psychiatric and neurological diseases in a person's medical history, no use of psychotropic medication and the ability to provide written informed consent into participation. All procedures were approved by the local institutional review board (reference EK 049/11) and conducted in accordance with the declaration of Helsinki [18].

Healthy subjects were recruited using postings and leaflets in and around the University Hospital of Aachen. Patients of pAD were recruited from the memory clinic of the neurological department of the University Hospital of Aachen. Diagnosis was established using cognitive testing, MRI and most importantly by cerebrospinal fluid markers, namely amyloid $\beta_{1-42}$ amyloid $\beta_{1-40}$, the ratio of amyloid $\beta_{1-42}$ and amyloid $\beta_{1-40}$ as well as total tau and phospho-tau.

\subsection{Study design and protocol}

The entire study spanned five examination days (T1-T5). T1 and T5 were pre and post-test sessions, while T2-T4 contained the rtfMRI neurofeedback training. Pre and post-test both encompassed a neuropsychological test battery as well as the spatial navigation task, consisting of a real-world part and a task during fMRI (see below for details). Details of the neurological, psychopathological and neuropsychological testing and the neurofeedback paradigm were described elsewhere [14] and are thus only briefly summarised below.

\subsection{Neurological, psychopathological and neuropsychological testing}

The neuropsychological battery used on pre and post-test days included tests primarily focusing on domains of memory. Key measures were the visual and verbal memory test (VVM) assessing visuo-spatial and verbal memory [19] and the Montreal Cognitive Assessment (MoCA) [20,21]. To assess pre-morbid intelligence the MWT-B - multiple choice word selection test - was used [22]. Moreover, on T1 only a short screening assessing neurological and psychiatric symptoms was performed, including the BDI-II a commonly used questionnaire to assess experienced symptoms of depression [23]. Furthermore we assessed tasks of the Wechsler Memory Scale Revised (WMS-R), namely on logical, visual as well as short term and working memory, the visual patterns test (VPT) as well as Trail-Making-Tests A and B (TMT-A/B). Detail on these tasks are given in the previously published work focusing on the rtfMRI neurofeedback training [14]. To avoid effects due to repeated testing, we employed alternate test versions for follow-up on T5, where available.

\subsection{Spatial navigation task}

The spatial navigation task contained two parts, a behavioural encoding part in which a novel route in an unknown environment was learned and then later a task during fMRI in which the route was to be recalled. The task took place on $\mathrm{T} 1$ and $\mathrm{T} 5$.

\subsubsection{Encoding}

For each subject one out of three routes (north, central and west) was randomly chosen. Each route was a tour of 1.5-2 km length on the campus of the Research Centre Jülich (Jülich, Germany). Routes were mostly exclusive and crossed only in few points. Subjects were guided along the path by the examiner and instructed to memorise as much detail as possible. At ten pre-defined waypoints a stop was made; the examiner then told the subject the name of the waypoint and asked the subject to memorise that location particularly well. Each tour lasted about $30 \mathrm{~min}$ per subject. For each of the two test days a different route was chosen. See Table 1 for an overview of the distribution of paths per time point and group.

\subsubsection{Memory task}

Before the scanning session, subjects were asked to recall and describe the previously encoded route. In addition, all subjects watched a 3-min time-lapse video of the previously encoded route to ensure sufficient memory. The task during scanning was split up into two parts, each containing five cycles of rest/recall (navigation)/decide (lasting 20/30/5 s). During rest subjects were asked to count backwards from 100. For recall, subjects were asked to recall a specified part of the encoded real-world route and to imagine walking along that route again. Then finally for decide, two pictures were presented to subjects and they were asked to decide by pressing a button, which of the displayed images was part of the route. After each part of the memory task a short debriefing was done enquiring the subjects whether they had difficulties to recall the previously learned route. In addition to the functional scan, a T1-weighted high-resolution anatomical scan of the brain was acquired as well.

Table 1

Distribution of paths by group and time point. Subjects were assigned to paths in a randomised manner.

\begin{tabular}{llclll}
\hline & \multicolumn{3}{c}{ Healthy controls } & & \multicolumn{2}{c}{ Patients } \\
\cline { 2 - 3 } \cline { 5 - 6 } & T1 & T5 & & T1 & T5 \\
\hline Central & 5 & 3 & & 3 & 1 \\
North & 3 & 4 & & 1 & 6 \\
West & 4 & 5 & 5 & 2 \\
\hline
\end{tabular}




\subsection{Neurofeedback training}

In brief, on $\mathrm{T} 2$ through $\mathrm{T} 4$ subjects trained to regulate activation of the left parahippocampal gyrus while recalling the footpath encoded on T1. The training consisted of four real-time runs per scanning session of which the first was used as a functional localiser identifying the target region for the training. The other three runs were actual training runs. During the training, rest and activation trials alternated each lasting $40 \mathrm{~s}$ with each run containing each trial eight times. Brain activation was visualised as a thermometer bar, with subjects being asked to fill it as much as possible during activation phases and empty it during rest phases. The results of the training itself were reported in detail in an earlier publication [14].

\subsection{Brain imaging}

All brain imaging was performed on a Siemens (Erlangen, Germany) MAGNETOM Trio whole-body 3T MR scanner using standard gradients and a 32-channel phased-array head coil for signal reception and the body coil for radio-frequency transmission. Participants laid head-first supine in the scanner. Foam padding was used within the head coil to limit movement. An MR-compatible mirror system was attached to the coil so that subjects could look out to the back of the scanner where an MR-compatible LED screen was mounted. To capture task responses a MR-compatible human input device was given to subjects. On all examination days, high-resolution anatomical scans using a magnetisation-prepared rapid gradient echo (MP-RAGE) sequence were acquired (TR $=2250 \mathrm{~ms}, \mathrm{TE}=3.03 \mathrm{~ms}$, flip angle $=9^{\circ}$, slice thickness $=1 \mathrm{~mm}$, $256 \times 256$ in-plane matrix, acquisition time: $5 \mathrm{~min} 14 \mathrm{~s}$ ). For the fMRI spatial navigation task, rtfMRI neurofeedback and functional localiser runs, an echo planar imaging sequence was used $(\mathrm{TR}=2000 \mathrm{~ms}$, $\mathrm{TE}=$ $62 \mathrm{~ms}$, flip angle $=79^{\circ}$, field-of-view $=192 \times 192,64 \times 64$ in-plane matrix, 32 slices with $3 \mathrm{~mm}$ thickness and an inter-slice-gap of $1.2 \mathrm{~mm}$, 140 whole brain volumes and $4 \mathrm{~min} 40 \mathrm{~s}$ acquisition time for the spatial navigation task, 240 whole-brain volumes and $8 \mathrm{~min}$ acquisition time for rtfMRI sessions).

\subsection{Analysis}

Analysis was focused on identifying differences in central tendency of responses between groups and over time points. The commonly used threshold of $p<.05$ was used merely as an orientation, but not as a hard cut-off due to the numerous problems associated with such an approach [for an extensive discussion see [24], and the related works].

\subsubsection{Behavioural data}

Behavioural data analysis was carried out using the statistical software and programming language $\mathrm{R}$ version 3.5 [25]. To assess differences in means between groups and time points a linear mixed model was fitted for each neuropsychological test limited to these subjects that were included in the spatial navigation data analysis. Both predictors were factors with two levels, here representing post-test and patients explicitly, thus the respective other level implicitly.

\subsubsection{Imaging data}

Brain imaging data was processed and analysed using the FSL [26-29] suite of imaging analysis tools. Functional images were slice scan time corrected, motion corrected, and motion parameters regressed out of the functional time courses, skull stripped and co-registered to skull-stripped anatomical images and a reference brain (MNI). Additionally, time courses from white matter and cerebrospinal fluid were regressed out of the data, which was then bandpass filtered (cutoffs 0.01 and $0.08 \mathrm{~Hz}$ ) and spatially smoothed with a Gaussian kernel of $6 \mathrm{~mm}$ FWHM.

For analysing data within groups data from all subjects and time points was averaged within a group and contrasted against rest-phases.
Results were thresholded at $Z \geq 2$ and cluster level $p<.05$.

As for analysing changes over time and differences between groups, we introduced random effects modelling. Here, results were thresholded at $Z \geq 2$ and cluster level $p<.05$. Due to their brevity of only $5 \mathrm{~s}$ per trial we did refrain from analysing activation during decision phases.

An additional analysis comparing groups at each time point under each condition was subsequently carried out making use of mixed modelling.

\section{Results}

\subsection{Sample characteristics}

Of the 21 subjects that were included in this analysis 12 were part of the healthy control group ( 6 female, 6 male) and 9 formed the patient group ( 2 female, 7 male). The mean age of healthy controls was 65.25 years (standard deviation $[S D]=6.326$ ), while the mean age of patients was 64.667 years $(\mathrm{SD}=8.261)$.

As for the assessment of symptoms of depression, the mean BDI-II score in healthy controls was 3 (SD $=3.643$ ), while in patients it was 5.778 (SD $=5.167)$. The pre-morbid intelligence quotient as assessed with the MWT-B was 126 (SD = 9.341) in healthy controls and 107.333 $(S D=14.832)$ in patients. An overview of sample characteristics can be found in Table 2 .

\subsection{Neuropsychology}

As this was described in detail for a larger sample in a previous publication [14], we only summarise the most important results for the subsample included here. Estimates are given for the patient group and the post-test.

Linear mixed models using time point and groups as predictors on the respective neuropsychological tests suggest an effect over time for the MoCA (estimate (est.) $=0.667$, error (err.) $=0.311, t(20)=2.142$, $p=.045$ ) as well as a difference between groups (est. $=-2.514$,

\section{Table 2}

Sample characteristics. Shown are either counts and range for categorical data or mean and SD for numeric data. Numeric data available in both groups were screened for differences between groups using t-tests, which suggested a difference between means for the MWT-B pre-morbid intelligence (marked by *). Categories for school years correspond to standard levels in the German Education system.

\begin{tabular}{|c|c|c|}
\hline & Healthy controls & Patients \\
\hline$n$ & 12 & 9 \\
\hline Age & $65.25( \pm 6.33)$ & $64.67( \pm 8.26)$ \\
\hline Female & 6 & 2 \\
\hline Male & 6 & 7 \\
\hline \multicolumn{3}{|l|}{ Education } \\
\hline Higher education & 4 & 2 \\
\hline 13 school years & 4 & 2 \\
\hline 12 school years & 2 & 0 \\
\hline 10 school years & 2 & 2 \\
\hline 9 school years or less & 0 & 3 \\
\hline \multicolumn{3}{|l|}{ Psychometrics } \\
\hline BDI-II & $3( \pm 3.64)$ & $5.78( \pm 5.17)$ \\
\hline MWT-B IQ* & $126( \pm 9.43)$ & $107.33( \pm 14.82)$ \\
\hline MoCA & $26.8( \pm 2.22)$ & $25.1( \pm 3.26)$ \\
\hline \multicolumn{3}{|l|}{ Cerebrospinal fluid markers } \\
\hline Amyloid $\beta_{1-42}(\mathrm{pg} / \mathrm{ml})$ & $\mathrm{n} / \mathrm{a}$ & 597.13 \\
\hline Amyloid $\beta_{1-40}(\mathrm{pg} / \mathrm{ml})$ & $\mathrm{n} / \mathrm{a}$ & $14,536.86$ \\
\hline$\beta_{1-42} / \beta_{1-40}$ Ratio & $\mathrm{n} / \mathrm{a}$ & 0.50 \\
\hline Total tau $(\mathrm{pg} / \mathrm{ml})$ & $\mathrm{n} / \mathrm{a}$ & 361.63 \\
\hline Phospho tau (pg/ml) & $\mathrm{n} / \mathrm{a}$ & 75.5 \\
\hline
\end{tabular}


Table 3

Results from the spatial navigation task during fMRI. Given are median values with median absolute deviation (MAD) scores in parentheses.

\begin{tabular}{llllll}
\hline & \multicolumn{2}{c}{ Healthy controls } & & \multicolumn{2}{c}{ Patients } \\
\cline { 2 - 3 } \cline { 5 - 6 } & T1 & T5 & & T1 & T5 \\
\hline Correct & $8.5(2.22)$ & $8.5(0.741)$ & & $9(1.48)$ & $8(2.97)$ \\
Incorrect & $0.5(0.741)$ & $1(1.48)$ & & $1(1.48)$ & $2(1.48)$ \\
No response & $0(0)$ & $0(0)$ & & $1(1.48)$ & $0(0)$ \\
\hline
\end{tabular}

err. $=1.085, t(19)=-2.318, p=.032)$, here reflecting an improvement in controls but not patients. For the VVM visuo-spatial memory task of the model suggested mainly an effect over time (est. $=16.952$, err. $=6.133, t(20)=2.764, p=.012$ ), but not group (est. $=-10.819$, err. $=10.043, t(19)=-1.077, p=.295)$. In the delayed recall condition in that task the pattern was similar over time (est. $=16.000$, err. $=5.385, t(20)=2.971, p=.008$ ) and group (est. $=-13.208$, err. $=9.645, t(19)=-1.369, p=.187)$. Modelling for all other administered neuropsychological tests is not reported here, for details on the further tests and how results changed over time in the supersample please see the respective paper [14].

\section{3. fMRI spatial navigation task}

\subsubsection{Behavioural}

The median amount of correct answers in the healthy control group was 8.5 at both T1 and T5, while in the pAD group it was 9 at $\mathrm{T} 1$ and 8 at T5. For the full breakdown of answers in the spatial navigation task during fMRI see Table 3.

\subsection{2. $f M R I$ results}

In patients, brain activation was found bilaterally in the inferior and middle frontal gyrus, prefrontal gyrus, the precuneus, medial temporal lobe and hippocampus formation, the posterior division of the cingulate, occipital lobe and cerebellar areas. Brain activation in controls generally was compatible with the findings in patients, but more pronounced and with larger clusters. Average activation in each group is visualised in Fig. 1.

When comparing time points within groups, controls showed bigger activation during the recall phase of the experiment in the pre-test compared to the post-test. Larger activation at the pre-test was found in the right precentral gyrus (BA 6) as well as the left occipital lobe. In patients, activation was increased in the post-test. Here, the right occipital lobe, middle frontal gyrus as well as the left frontal lobe showed increased activation compared to the pre-test. Additionally, the cerebellum contained clusters of increased activation bilaterally. For the directions post $>$ pre in controls and pre $>$ post in patients no differences were found.

Assessing differences between groups, for the navigation phase it was found that in the pre-test controls displayed greater activation in the left lingual gyrus and the right middle frontal gyrus. Patients showed larger activation in the left middle temporal gyrus and left medial frontal gyrus as well as in the cingulate gyrus and medial temporal lobe in the right hemisphere. In the post-test these patterns remained largely unchanged. Differences between groups are visualised in Figs. 2 and 3. Additionally, all details regarding differences between groups and over time in activation during navigation phases can be found in Table 4.

\subsection{Subjective rating}

Regarding the subjective rating of the difficulty of the task the results were as follows: in the healthy control group one subject reported difficulties to recall the learned itinerary at one time point (T1), while in the $\mathrm{pAD}$ group one subject reported difficulties at both time points and another subject reported difficulties for one run at one time point (T1). All other subjects reported that they were able to recall the route well.

\section{Discussion}

The present work describes a task on visuo-spatial memory combined with visual imagery of spatial navigation in a novel environment. Herein, subjects first encoded a previously unknown real-world itinerary in an unfamiliar environment into memory and were then asked to recall and imagine it during a subsequent task employing fMRI. Additionally, the task was carried out before and after a rtfMRI neurofeedback-based training of the left parahippocampal gyrus that reused the itinerary encoded into memory on T1 to elicit targeted activation in the left parahippocampal gyrus and induce improvements in the cognitive domain of visuo-spatial memory (as measured by the VVM neuropsychological test).

Results show that brain activation in both healthy control subjects as well as patients of prodromal $\mathrm{AD}$ was related to the task's cognitive demands, but differences over time showed different patterns between the groups. Also, activation during the task was generally weaker in patients suffering from $\mathrm{AD}$ than in controls, which is a documented effect in manifest $\mathrm{AD}[30,31]$. In both groups, activation of the left parahippocampal gyrus remained unchanged between T1 and T5 in the fMRI spatial navigation task and it did not display activation during the fMRI spatial navigation task in general.

Overall, not many changes over time and differences between groups were found. Nonetheless, the few changes that were found were directed differently between the groups. Activation was larger in the pre-test than in the post-test in controls but the opposite pattern was found for patients.

The behavioural results from the fMRI task suggest that it was relatively easy for both included groups. This notion is further supported by elderly adults showing difficulties with more complex navigation tasks [32], which were not found in the present work. Observing potential changes in cognitive performance within the context of this task is thus difficult as there is not too much room for improvement.

However, considering the range of values of correct responses in the patient group, the task likely was more difficult for patients and probably became more difficult with increased symptom severity. This line of thought appears straightforward as deteriorating performance in cognitive tests is well-documented in this disease [33,34] and general cognitive decline is an unquestionable hallmark symptom of it [35]. Considering the subjective rating of the task's difficulty there does not seem to be any difference between the groups but it is established that patients of AD often display anosognosia [36-38]. However, note that the presence of anosognosia in patients of $\mathrm{AD}$ was not assessed in the context of this study, so research in the future should consider including such an assessment.

Brain activation patterns found during the navigation phases of the fMRI spatial navigation task were generally compatible with what was previously reported regarding cognitive demands for the visuo-spatial memory portion of the employed task [39-41]. Activation patterns further resemble those found during the previously published data on the rtfMRI neurofeedback training sessions [14], which also required recalling visuo-spatial memory contents. The training sessions were in fact based on the itinerary from T1. However, both the present task and the rtfMRI paradigm did not only require subjects to recall the memorised itinerary, but subjects were explicitly instructed to imagine walking along it. The array of occipital, inferior parietal and frontal regions which were found to be activated during the task were previously reported in the literature as being active in paradigms incorporating visuo-spatial memory and visual imagery [42-44]. Also, cerebellar activation has been reported in settings of motor imagery [45], which is without doubt a component of the task requirements and straightforward given the role of the cerebellum in planning of motor 


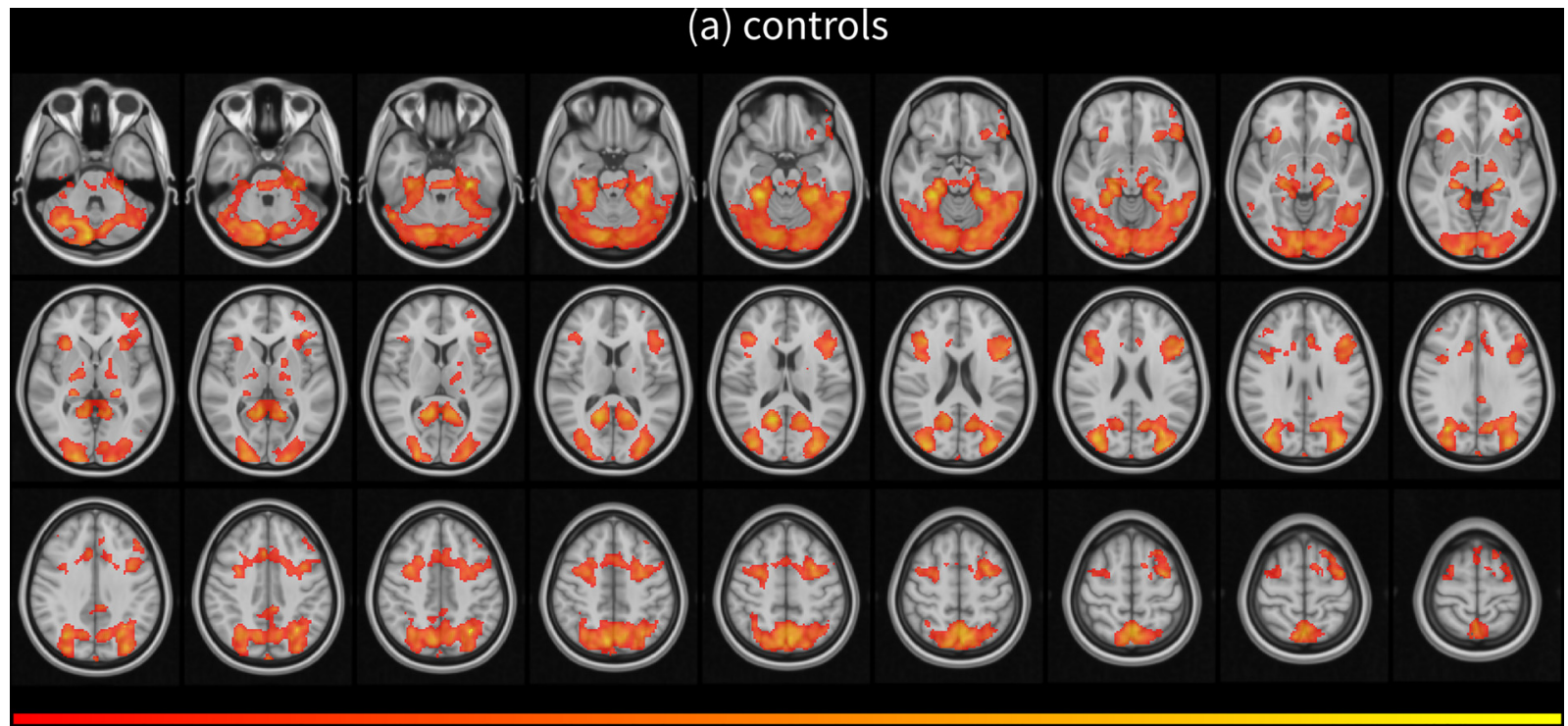

3.00

7.41

(b) patients
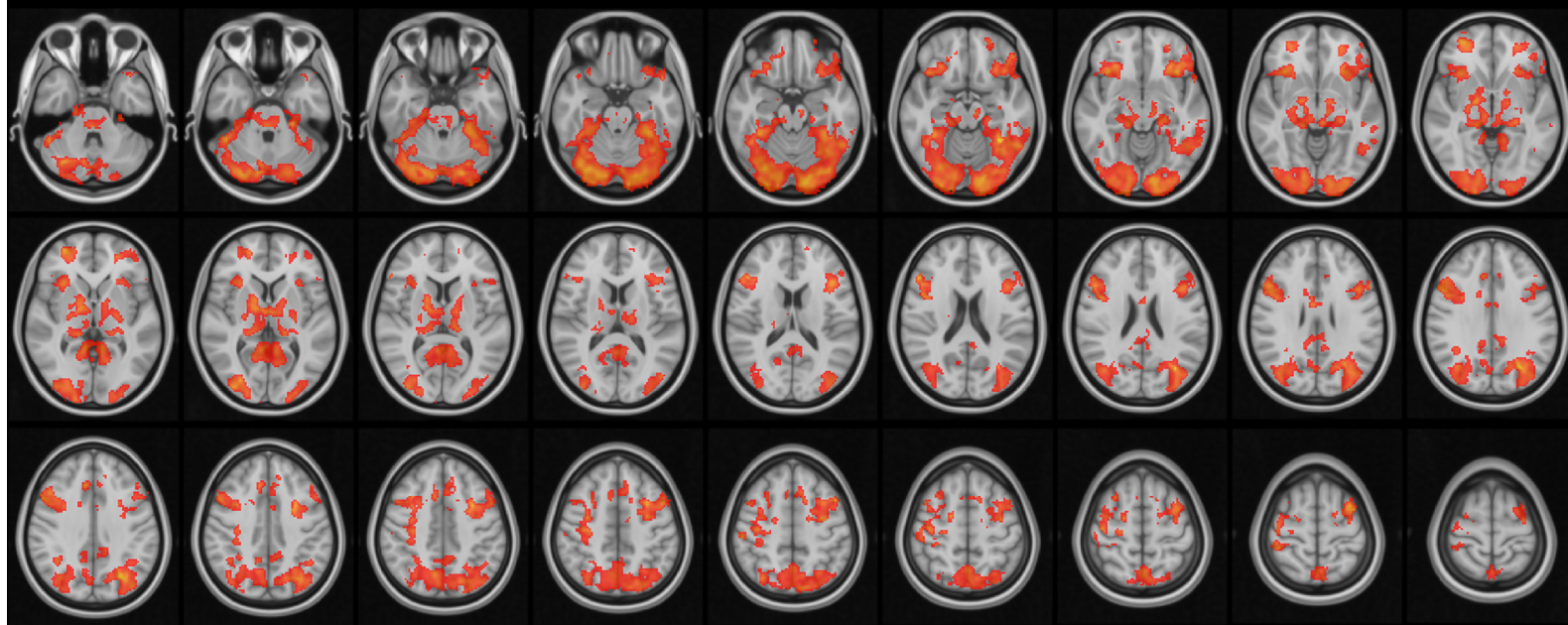

3.00

6.25

Fig. 1. Average activation for both groups during navigation phases. Activation is averaged across all subjects and time points within each group. Results are thresholded at $Z>3$ and cluster-level $p<.05$. Data is projected onto the ICBM Average Brain, copyright (C) 1993-2009 Louis Collins, McConnell Brain Imaging Centre, Montreal Neurological Institute, McGill University.

actions [46-48]. Admittedly, the region the training focused on, the left parahippocampal gyrus was not part of the regions that displayed activation changes in the presently discussed fMRI paradigm. Why this is the case remains unclear, but considering that parahippocampal activation did remain essentially constant over the course of the training despite being subjects being able to activate the region when asked to [14]. This is at least in line with the data and further points towards the notion that the training here appeared to have more effect on associated regions and networks (see below).

Regarding the regions that display larger activation in patients compared to controls there is some overlap with the default mode network $[49,50]$. Here, these regions encompass frontal areas, the cingulate and also the medial temporal lobe. In patients of $\mathrm{AD}$, it has been established that connectivity of the default mode network is impaired [51-53] - in fact this is the most reproducible and robust finding regarding fMRI-based functional connectivity in $\mathrm{AD}$. In addition to potential involvement of the default mode network a spatial navigation network has also been suggested in the literature [54]. This network is thought to be consisted to a large extent of frontal loci and to be primarily recruited in elderly when performing spatial navigation tasks [54]. The concept of the spatial navigation network also appears to be in line with the here reported main fMRI findings, when considering the larger activation in the regions related to the default mode network in patients compared to controls as part of a compensatory response to a disintegrating connectivity to meet the task's demands - but given the available data this cannot be concluded with certainty. The concept of compensatory brain activation to work against the damage incurred by the neurodegeneration of $\mathrm{AD}$ is not new and has previously been discussed $[55,6]$. Due to the fact that patients included in this study were primarily in rather early stages of the disease, explaining the observed effect on activation with this kind of response is straightforward. That the activation in the aforementioned regions is even larger after the 

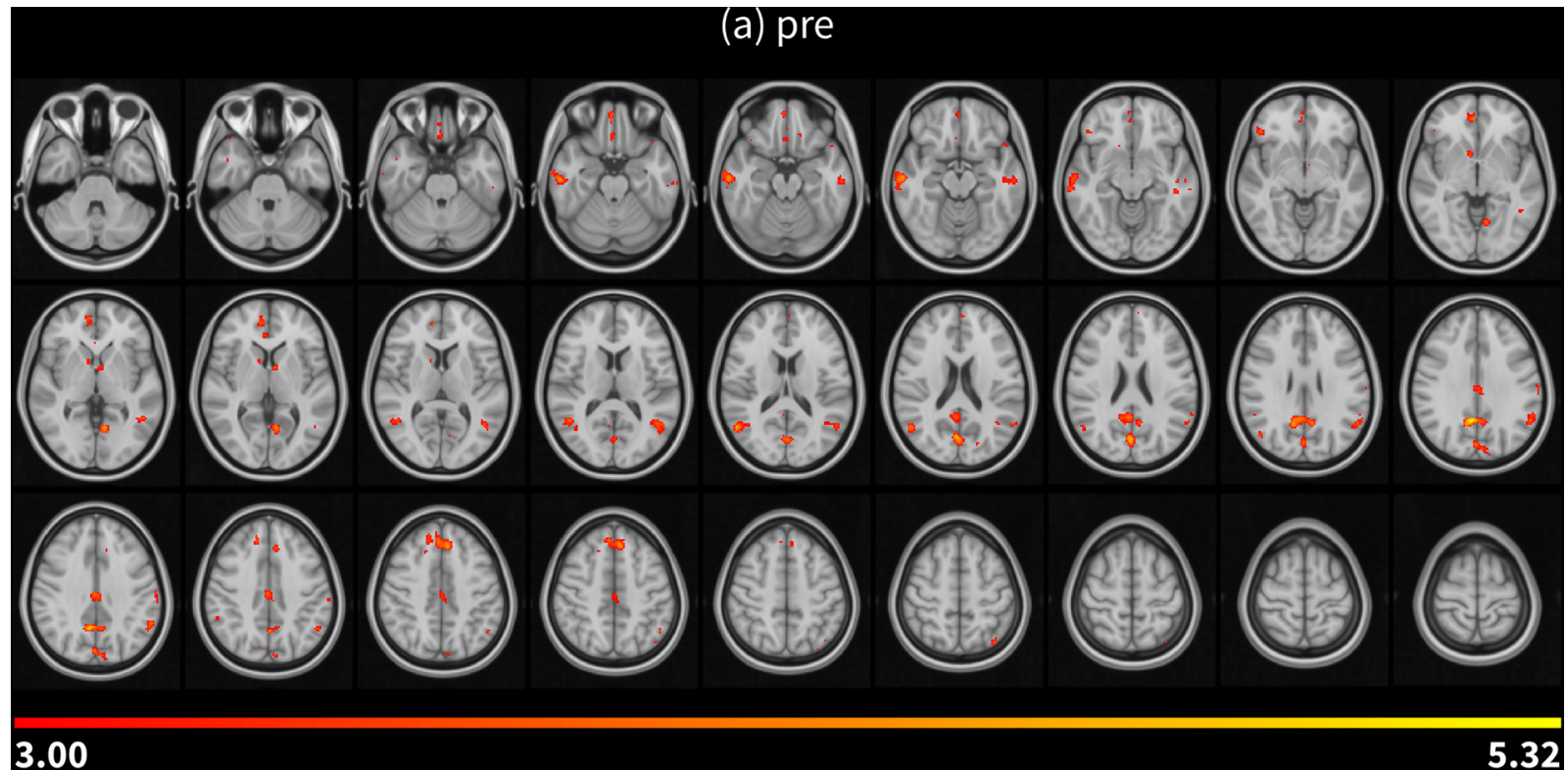

(b) post
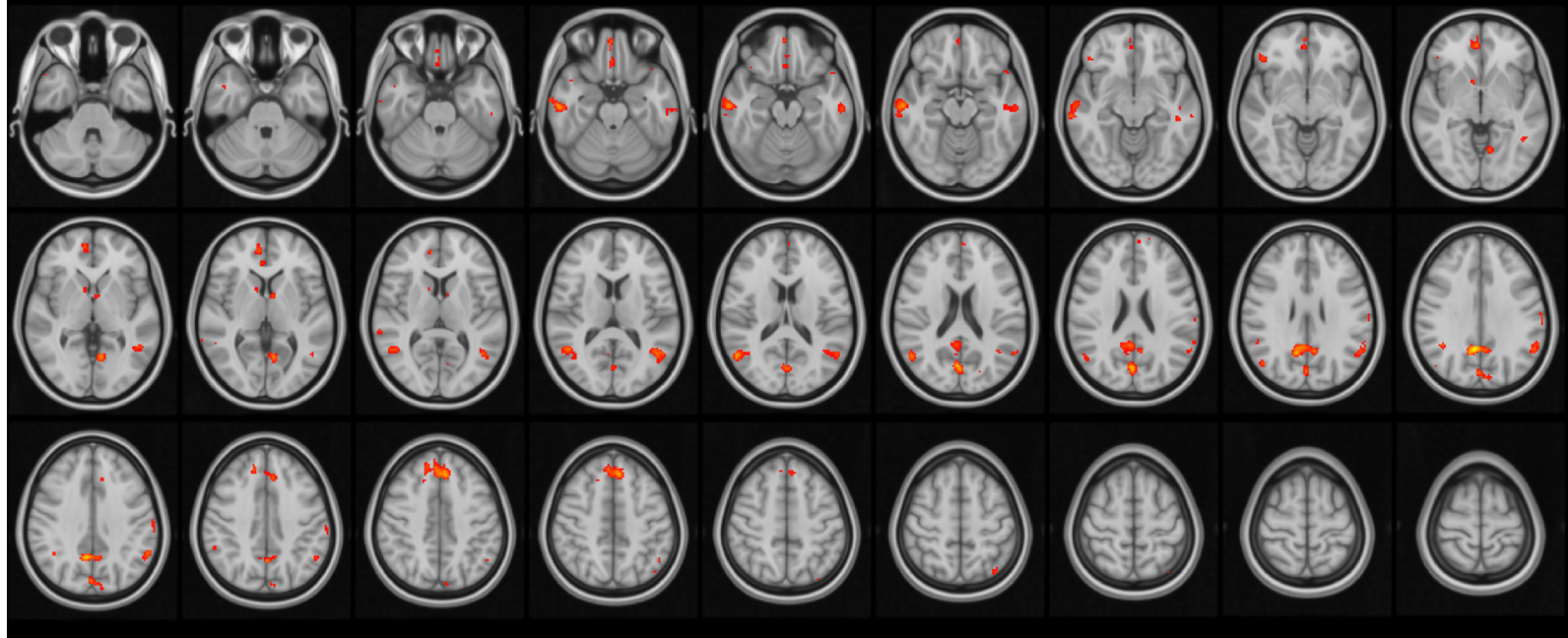

\subsection{0}

Fig. 2. Activation at pre and post-test for patients $>$ controls. Activation is thresholded at $Z>3$ and cluster-level $p<0.5$. Data is projected onto the ICBM Average Brain, copyright (C) 1993-2009 Louis Collins, McConnell Brain Imaging Centre, Montreal Neurological Institute, McGill University.

rtfMRI training could further be seen as an effect of the training on the compensatory response within the default mode and spatial navigation networks, but given the data available here this conclusion has to remain speculative.

In controls there is not much activation that is larger than in patients and additionally only few longitudinal changes. Generally, the longitudinal change observed in this group can be seen as an increase of cerebral efficiency induced by the training [56]. This interpretation would also be compatible with the previously reported findings regarding the activation during rtfMRI neurofeedback training [14], which largely remained constant for controls while cognitive changes were nonetheless found in the targeted domain.

The lingual gyrus is one region displaying greater activation in healthy controls compared to patients. It has been linked to visual attention [57] and furthermore, it has been associated with visual imagery and creativity $[58,59]$. Assuming that the task was considerably easier for healthy subjects than for patients it seems reasonable that this region was consistently more activated during the fMRI spatial navigation task in controls compared to patients. Due to likely better memory of the encoded itinerary in controls, visual imagery of it should be easier and accomplished more successfully, potentially explaining the larger activation here.

With regards to longitudinal effects in controls there is larger activation in the pre-test in the left cuneus and right precentral gyrus. Involvement of both regions makes sense for the present task, but the lack of notable changes might again simply be because the task was much too easy for a healthy person, which is being supported by the behavioural data. The overall duration of the training should also be considered here. Real-time fMRI neurofeedback training spanned three training days, with the added pre and post-test the entire protocol usually lasted about 2.5 weeks. This might be too short to elicit broad effects and more training - in the form of more training days and/or 

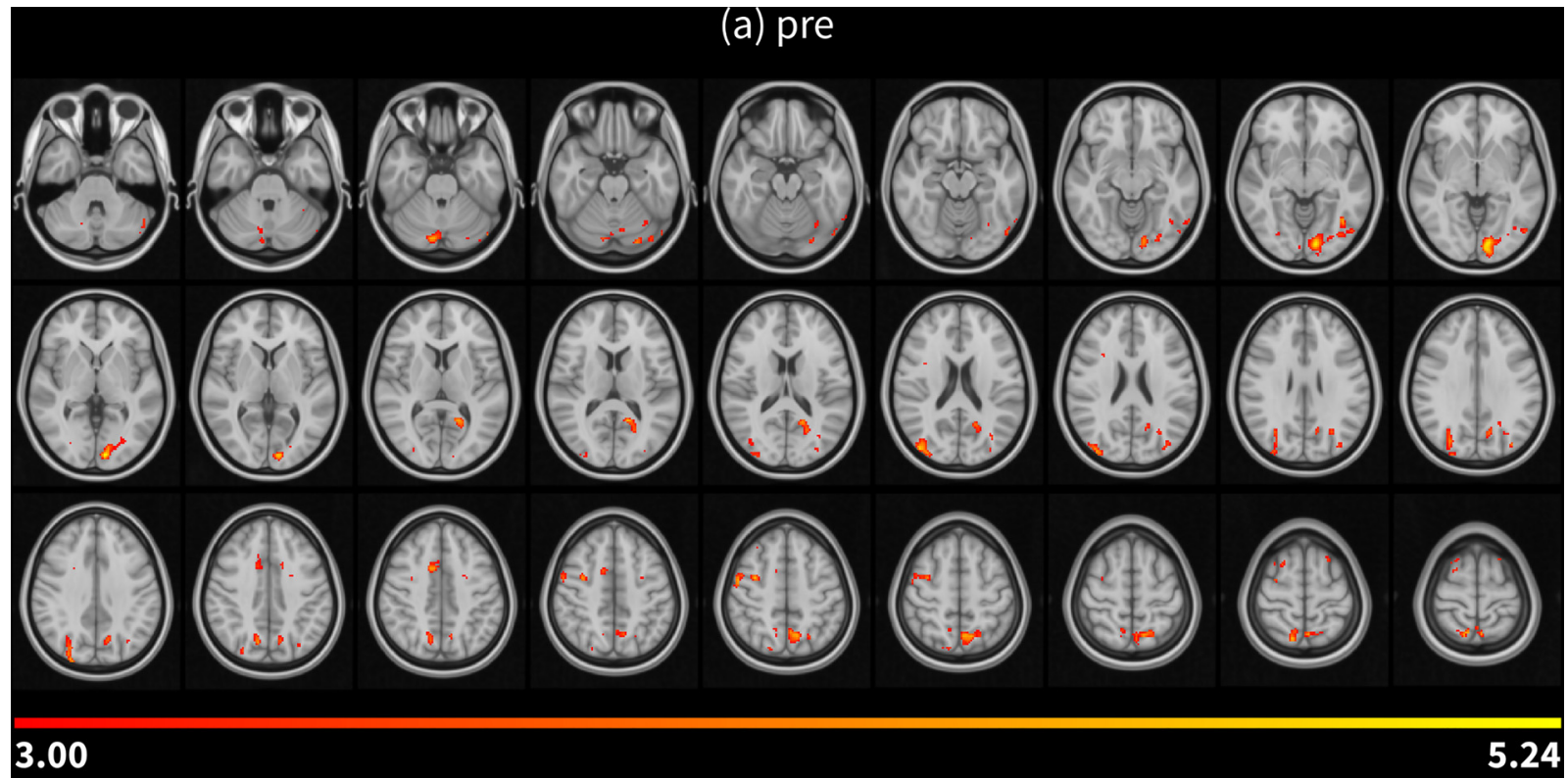

(b) post
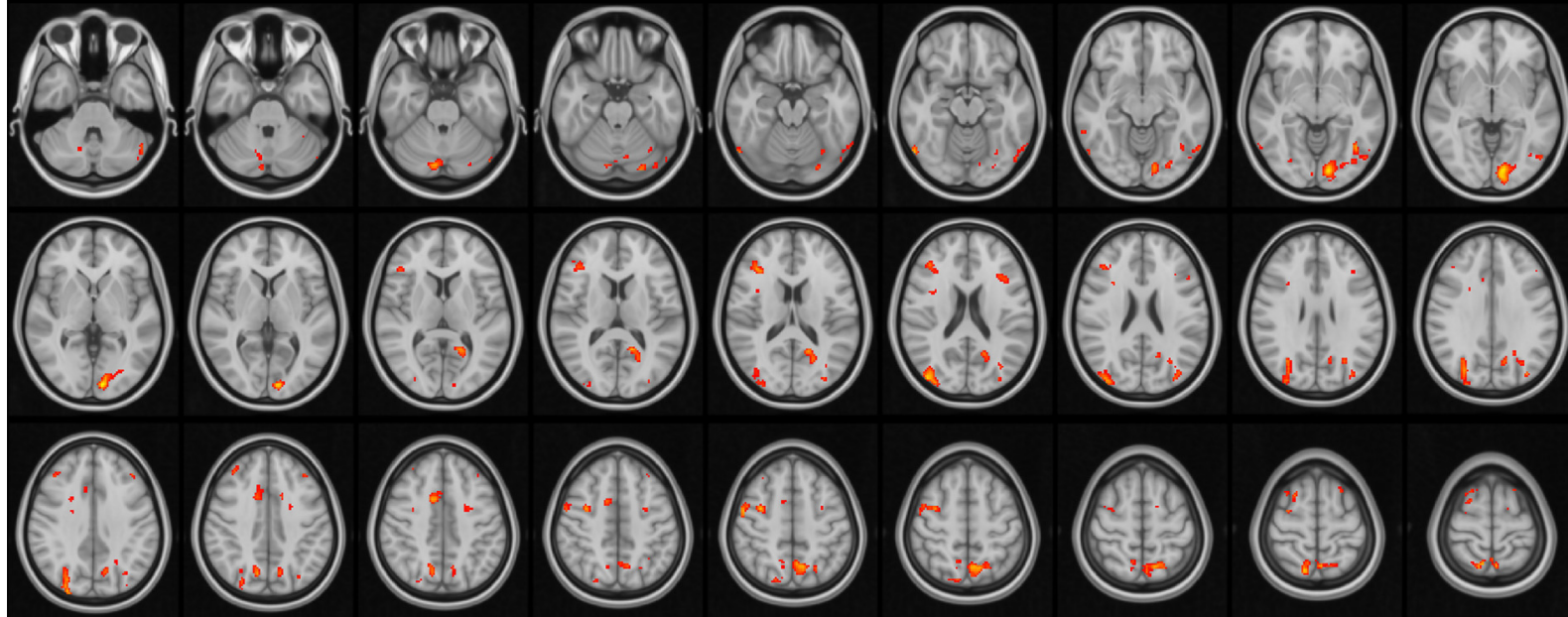

\subsection{0}

Fig. 3. Activation at pre and post-test for controls $>$ patients. Activation is thresholded at $Z>3$ and cluster-level $p<0.5$. Data is projected onto the ICBM Average Brain, copyright (C) 1993-2009 Louis Collins, McConnell Brain Imaging Centre, Montreal Neurological Institute, McGill University.

longer individual sessions - might be needed. Previous cognitive training studies have used much longer paradigms [60] and a link between duration of training and training success has been established [61].

The behavioural task during fMRI was mainly designed as a proofof-concept to ensure that brain activation relevant to the task is elicited and to ensure that subjects were indeed able to remember the previously learned itinerary. The paradigm was thus not very challenging especially to healthy controls, but some patients of AD seemed to face difficulties as indicated by the amount of correct responses given. It is clear that at some point in the progression of $\mathrm{AD}$ pathology the task does eventually become challenging. Regardless, the subjective rating of the task's difficulty did not indicate any influence of disease progression or any other measure on how challenging subjects perceived the task. Given that the subjective rating of the task's difficulty was a dichotomous choice, caution is however advised in interpretation of this finding and a more fine-grained scale would likely have shown more variance.

Differences in prerequisites before beginning the training are an additional issue that is highlighted by the present paper. From the data on pre-morbid intelligence and depression as well as when considering levels of education it is apparent that both groups had different starting conditions, which could very well affect the outcome. In the context of $\mathrm{AD}$ this is a somewhat serious issue as it is known that certain factors, like the level of education, are risk factors for an eventual onset of $\mathrm{AD}$ [62], future studies should thus consider matching patients and controls based on demographic variables.

The current task did not employ a control group receiving sham feedback, which limits the generalisability of the present proof-ofconcept results. Such a group, despite being small, was included in the design [14], but due to additional missing data could not be included in the analysis of the fMRI spatial navigation task. While this makes it 
Table 4

Activation during navigation phases. Activation is based on thresholding at $Z>2.5$ and cluster-wise $p<.05$. Coordinates are given for the peak of activation. As the coordinates are based on functional voxels with a resolution of $3 \mathrm{~mm}^{3}$ accuracy is limited. Abbreviations: BA - Brodmann area; $\mathrm{L}-$ left hemisphere; $\mathrm{R}$ - right hemisphere.

\begin{tabular}{|c|c|c|c|c|c|c|}
\hline Region & BA & $\mathrm{mm}^{3}$ & $Z$ (max) & $\operatorname{Max} X$ & $\operatorname{Max} Y$ & $\operatorname{Max} Z$ \\
\hline \multicolumn{7}{|c|}{ Between group comparisons } \\
\hline \multicolumn{7}{|c|}{ Post test controls > patients } \\
\hline L lingual gyrus & & 11,870 & 5.29 & -8 & -90 & 0 \\
\hline $\mathrm{R}$ middle frontal gyrus & 6 & 5124 & 4.73 & 34 & -2 & 48 \\
\hline \multicolumn{7}{|l|}{ Post test patients > controls } \\
\hline L middle temporal gyrus & 39 & 3691 & 4.26 & -52 & -60 & 14 \\
\hline $\mathrm{R}$ anterior cingulate & 32 & 2876 & 4.26 & 4 & 48 & -6 \\
\hline $\mathrm{R}$ cingulate & 31 & 2542 & 5.39 & 6 & -54 & 32 \\
\hline $\mathrm{R}$ middle temporal gyrus & 19 & 1580 & 4.5 & 54 & -62 & 16 \\
\hline L medial frontal gyrus & & 1215 & 4.57 & -6 & 32 & 44 \\
\hline $\mathrm{R}$ middle temporal gyrus & & 1077 & 4.41 & 58 & -18 & -22 \\
\hline \multicolumn{7}{|l|}{ Pre test controls > patients } \\
\hline L lingual gyrus & & 8781 & 5.24 & -8 & -90 & 0 \\
\hline $\mathrm{R}$ middle frontal gyrus & 6 & 2368 & 4.65 & 34 & -2 & 48 \\
\hline L cerebellar gyrus VIII & & 1459 & 4.37 & -30 & -56 & -54 \\
\hline \multicolumn{7}{|l|}{ Pre test patients > controls } \\
\hline L middle temporal gyrus & 39 & 3558 & 4.13 & -52 & -60 & 14 \\
\hline $\mathrm{R}$ anterior cingulate & 32 & 2893 & 4.13 & 4 & 48 & -6 \\
\hline $\mathrm{R}$ cingulate gyrus & 31 & 2628 & 5.32 & 6 & -54 & 32 \\
\hline $\mathrm{R}$ middle temporal gyrus & 19 & 1270 & 4.46 & 54 & -62 & 16 \\
\hline L medial frontal gyrus & & 1060 & 4.48 & -6 & 32 & 44 \\
\hline $\mathrm{R}$ middle temporal gyrus & & 993 & 4.33 & 58 & -18 & 22 \\
\hline Bilateral cingulate & & 728 & 4.01 & 2 & -20 & 36 \\
\hline \multicolumn{7}{|l|}{ Within group comparisons } \\
\hline \multicolumn{7}{|c|}{ Controlspost $>$ pre } \\
\hline \multicolumn{7}{|l|}{$\mathrm{n} / \mathrm{a}$} \\
\hline \multicolumn{7}{|l|}{ Controls pre > post } \\
\hline R precentral gyrus & 6 & 2196 & 3.7 & 56 & 0 & 8 \\
\hline L cuneus & & 5124 & 4.73 & 34 & -2 & 48 \\
\hline \multicolumn{7}{|l|}{ Patients post > pre } \\
\hline R superior occipital lobe & & 4083 & 3.98 & 36 & -78 & 38 \\
\hline $\mathrm{R}$ middle frontal gyrus & & 3795 & 4.01 & 40 & 10 & 54 \\
\hline $\mathrm{L}$ declive & & 2411 & 3.57 & -46 & -60 & -22 \\
\hline R cerebellar tonsil & & 1108 & 3.81 & 24 & -38 & -44 \\
\hline L inferior frontal gyrus & & 731 & 3.73 & -46 & 26 & 16 \\
\hline $\begin{array}{l}\text { Patients pre > post } \\
\mathrm{n} / \mathrm{a}\end{array}$ & & & & & & \\
\hline
\end{tabular}

difficult to delineate which results are mere effects due to practice and repeated testing, we are confident that the results cannot be explained as mere repetition effects due to the diverging findings between the groups and the use of alternate tests wherever possible. Nonetheless this is clearly a limitation of the present paradigm and should be sorted out in subsequent works.

Finally, as touched upon in our paper that focused on the rtfMRI neurofeedback training [14], the question of transfer is raised in the context of the present paradigm. Transfer is the application of an ability that was learned in one domain in another, different domain $[63,64]$. As outlined above we have found improved performance in both groups in a neuropsychological test on visuo-spatial memory. That specific task required subject to encode a path outlined on a map for $2 \mathrm{~min}$ into memory and then draw it from memory into an empty map directly immediately afterwards and after a delay of $45-60 \mathrm{~min}$. While the cognitive requirements of that neuropsychological task surely overlap to some extent with the cognitive requirement of the training task, one would assume that the fMRI spatial navigation task employed here is even closer to the training task. However, there does not seem to be an improvement in task performance. Possibly, the recall performance itself was improved, but the effect was too subtle to affect the forced choice task, but this has to remain speculation. Generally, whether effects induced by rtfMRI neurofeedback training transfer into other domains has so far not been researched well. However, especially in a context like $\mathrm{AD}$ it is crucial that effects not only do persist, but also generalise into other cognitive domains to enable an overall quality of life improvement for affected persons. Future research, especially when targeting cognition with rtfMRI neurofeedback training, should aim to sort out under which conditions transfer can be achieved in such a setting and how it generalises into real-world tasks.

While results of enhanced cognition in $\mathrm{AD}$ are encouraging and should be further researched, it should be kept in mind that a rtfMRI neurofeedback training approach is unlikely to halt neurodegeneration and cognitive decline, both in healthy adults and in patients of $\mathrm{AD}$, but instead may provide a training or enhancement of cognitive reserve [for a discussion of the concept of cognitive reserve see [65]]. As long as no cure is available for $\mathrm{AD}$ any approach that prolongs a state of proper cognitive functioning might be desirable.

Possible routine clinical use of this technique requires further research and this paper as well as the preceding one focusing primarily on the properties of the neurofeedback training itself can only provide first insight into this matter. Recent works have shown that effects from rtfMRI neurofeedback training can persist for an extended amount of time [66-68], pointing towards the potential feasibility and fruitfulness of clinical use of this method. A major downside of rtfMRI training is the relatively high cost involved and the large amount of time required to carry it out even in a single subject, so future studies should aim at optimising study protocols. Additionally, subsequent work should include larger amounts of subjects to enhance statistical power, enable detection of small effects and also gather more long-term data.

\section{Limitations}

This work has some limitations. First, the ceiling effects present in the healthy control group render interpretation of data for this group difficult. As a comparison between healthy subjects and patients of prodromal AD was the goal here, the task had to be suitable for the patient group as well. Future works should seek to employ more finegrained measurements allowing more variance in the healthy group whilst maintaining comparability between both groups. Second, sample sizes are limited, consequently illustrating the preliminary nature of this work. Especially for the patient group recruitment turned out to be rather difficult, suggesting that in this context real-time fMRI neurofeedback studies need to make sure not to overstrain patients (but at the same time conduct proper training).

\section{Conclusions}

This work shows that while rtfMRI neurofeedback training can lead to improvements in cognitive ability in healthy elderly and patients of $\mathrm{AD}$, these effects may not transfer broadly. Additionally, it appears that the conducted training impacted brain functioning with regards to the compensatory response elicited by deteriorating cerebral organisation..

\section{Author contributions}

$\mathrm{CH}$ wrote the first draft of the manuscript, took part in recruiting subjects and acquiring data; carrying out data analysis and interpreting the data. NN, HK, and SK took part in recruiting subjects and acquiring data as well as designing the study. CM took part in recruiting subjects and acquiring data. RG and AH contributed to setting up the real-time fMRI paradigm and provided assistance with fMRI analysis. NS contributed to the design of the study and provided MR infrastructure. JS contributed to the design of the study. MR took part in study design. KR contributed to the design of the study, acquired funding, facilitated recruitment of patients, took part in interpretation of data, and revised 
the drafts of the manuscript. All authors read and approved the final manuscript.

\section{Conflict of interest}

The authors declare that there is no conflict of interest.

\section{Funding}

The project and the position of $\mathrm{CH}$ during the project was funded by the Alzheimer Forschung Initiative e.V. (AFI 13812 to KR). KR was additionally funded by the German Ministry of Education and Research (BMBF 01GQ1402). The funding agencies had no influence on study design, collection, analysis and interpretation of data or writing of the manuscript.

\section{Acknowledgements}

We thank all subjects taking part in this study for their collaboration and interest in this research. Additionally, we would like to thank Anna Fackler for supporting data analysis. Also, the authors would like to thank the staff from the INM-4 of the Research Centre Jülich and everyone else who helped out with various issues and technical problems regarding the study.

\section{References}

[1] K. Ubhi, E. Masliah, Alzheimer's disease: recent advances and future perspectives, J. Alzheimer's Dis. 33 (Suppl. 1) (2013) S185-S194, https://doi.org/10.3233/jad2012-129028.

[2] C.P. Ferri, M. Prince, C. Brayne, H. Brodaty, L. Fratiglioni, M. Ganguli, K. Hall, K. Hasegawa, H. Hendrie, Y. Huang, A. Jorm, C. Mathers, P.R. Menezes, E. Rimmer, M. Scazufca, Global prevalence of dementia: a Delphi consensus study, Lancet 366 (9503) (2005) 2112-2117, https://doi.org/10.1016/S0140-6736(05)67889-0.

[3] E.M. Aminoff, K. Kveraga, M. Bar, The role of the parahippocampal cortex in cognition, Trends Cogn. Sci. 17 (8) (2013) 379-390, https://doi.org/10.1016/j.tics. 2013.06.009.

[4] N.M. van Strien, N.L.M. Cappaert, M.P. Witter, The anatomy of memory: an interactive overview of the parahippocampal-hippocampal network, Nat. Rev. Neurosci. 10 (4) (2009) 272-282, https://doi.org/10.1038/nrn2614.

[5] H. Braak, E. Braak, Neuropathological stageing of Alzheimer-related changes, Acta Neuropathol. 82 (4) (1991) 239-259, https://doi.org/10.1007/BF00308809.

[6] N.A. Bishop, T. Lu, B.A. Yankner, Neural mechanisms of ageing and cognitive decline, Nature 464 (7288) (2010) 529-535, https://doi.org/10.1038/nature08983.

[7] T. Hedden, J.D.E. Gabrieli, Insights into the ageing mind: a view from cognitive neuroscience, Nat. Rev. Neurosci. 5 (2) (2004) 87-96, https://doi.org/10.1038/ nrn1323.

[8] H. Christensen, What cognitive changes can be expected with normal ageing? Aust. N. Z. J. Psychiatry 35 (6) (2001) 768-775, https://doi.org/10.1046/j. 1440-1614. 2001.00966.x.

[9] K. Emmert, R. Kopel, J. Sulzer, A.B. Brühl, B.D. Berman, D.E. Linden, S.G. Horovitz, M. Breimhorst, A. Caria, S. Frank, S. Johnston, Z. Long, C. Paret, F. Robineau, R. Veit, A. Bartsch, C.F. Beckmann, D. Van De Ville, S. Haller, Meta-analysis of realtime fMRI neurofeedback studies using individual participant data: how is brain regulation mediated? NeuroImage 124 (2016) 806-812, https://doi.org/10.1016/j. neuroimage.2015.09.042.

[10] R.T. Thibault, A. MacPherson, M. Lifshitz, R.R. Roth, A. Raz, Neurofeedback with fMRI: a critical systematic review, Neurolmage 172 (2018) 786-807, https://doi. org/10.1016/j.neuroimage.2017.12.071.

[11] S. Kim, N. Birbaumer, Real-time functional MRI neurofeedback, Curr. Opin. Psychiatry 27 (5) (2014) 332-336, https://doi.org/10.1097/YCO. 0000000000000087

[12] G. Zhang, L. Yao, H. Zhang, Z. Long, X. Zhao, Improved working memory performance through self-regulation of dorsal lateral prefrontal cortex activation using real-time fMRI, PLoS ONE 8 (8) (2013) e73735, https://doi.org/10.1371/journal. pone.0073735.

[13] F. Scharnowski, R. Veit, R. Zopf, P. Studer, S. Bock, J. Diedrichsen, R. Goebel, K. Mathiak, N. Birbaumer, N. Weiskopf, Manipulating motor performance and memory through real-time fMRI neurofeedback, Biol. Psychol. 108 (2015) 85-97, https://doi.org/10.1016/j.biopsycho.2015.03.009.

[14] C. Hohenfeld, N. Nellessen, I. Dogan, H. Kuhn, C. Müller, F. Papa, S. Ketteler, R. Goebel, A. Heinecke, N.J. Shah, J.B. Schulz, M. Reske, K. Reetz, Cognitive improvement and brain changes after real-time functional MRI neurofeedback training in healthy elderly and prodromal Alzheimer's disease, Front. Neurol. 8 (2017) 1-15, https://doi.org/10.3389/fneur.2017.00384.

[15] B. Dubois, H.H. Feldman, C. Jacova, J.L. Cummings, S.T. Dekosky, P. BarbergerGateau, A. Delacourte, G. Frisoni, N.C. Fox, D. Galasko, S. Gauthier, H. Hampel,
G.A. Jicha, K. Meguro, J. O’Brien, F. Pasquier, P. Robert, M. Rossor, S. Salloway, M. Sarazin, L.C. de Souza, Y. Stern, P.J. Visser, P. Scheltens, Revising the definition of Alzheimer's disease: a new lexicon, Lancet Neurol. 9 (11) (2010) 1118-1127, https://doi.org/10.1016/S1474-4422(10)70223-4.

[16] C.R. Jack, D.A. Bennett, K. Blennow, M.C. Carrillo, B. Dunn, S.B. Haeberlein, D.M. Holtzman, W. Jagust, F. Jessen, J. Karlawish, E. Liu, J.L. Molinuevo, T. Montine, C. Phelps, K.P. Rankin, C.C. Rowe, P. Scheltens, E. Siemers, H.M. Snyder, R. Sperling, C. Elliott, E. Masliah, L. Ryan, N. Silverberg, NIA-AA Research Framework: toward a biological definition of Alzheimer's disease, Alzheimer's Dement. 14 (4) (2018) 535-562, https://doi.org/10.1016/j.jalz.2018. 02.018.

[17] R.C. Oldfield, The assessment and analysis of handedness: the Edinburgh inventory, Neuropsychologia 9 (1) (1971) 97-113, https://doi.org/10.1016/0028-3932(71) 90067-4.

[18] World Medical Association, World Medical Association Declaration of Helsinki, JAMA 310 (20) (2013) 2191, https://doi.org/10.1001/jama.2013.281053.

[19] D. Schellig, B. Schächtele, Visueller \& Verbaler Merkfähigkeitstest, Pearson Assessment \& Information, Frankfurt am Main, Germany, 2001.

[20] A.S. Costa, B. Fimm, P. Friesen, H. Soundjock, C. Rottschy, T. Gross, F. Eitner, A. Reich, J.B. Schulz, Z.S. Nasreddine, K. Reetz, Alternate-form reliability of the Montreal cognitive assessment screening test in a clinical setting, Dement. Geriatr. Cogn. Disorders 33 (6) (2012) 379-384, https://doi.org/10.1159/000340006.

[21] Z.S. Nasreddine, N.A. Phillips, V. Bédirian, S. Charbonneau, V. Whitehead, I. Collin, J.L. Cummings, H. Chertkow, The Montreal Cognitive Assessment, MoCA: a brief screening tool for mild cognitive impairment, J. Am. Geriatr. Soc. 53 (4) (2005) 695-699, https://doi.org/10.1111/j. 1532-5415.2005.53221.x.

[22] S. Lehrl, Mehrfachwahl-Wortschatz-Intelligenztest MWT-B, fifth edition, Spitta Verlag, Balingen, Germany, 2005.

[23] A.T. Beck, R.A. Steer, R. Ball, W.F. Ranieri, Comparison of Beck Depression Inventories-IA and-II in psychiatric outpatients, J. Pers. Assess. 67 (3) (1996) 588-597, https://doi.org/10.1207/s15327752jpa6703_13.

[24] R.L. Wasserstein, N.A. Lazar, The ASA's statement on p-values: context, process, and purpose, Am. Stat. 70 (2) (2016) 129-133, https://doi.org/10.1080/00031305. 2016.1154108.

[25] R Core Team, R: A Language and Environment for Statistical Computing, R Foundation for Statistical Computing, Vienna, Austria, 2018.

[26] M. Jenkinson, C.F. Beckmann, T.E. Behrens, M.W. Woolrich, S.M. Smith, FSL, NeuroImage 62 (2) (2012) 782-790, https://doi.org/10.1016/j.neuroimage.2011. 09.015 .

[27] M.W. Woolrich, B.D. Ripley, M. Brady, S.M. Smith, Temporal autocorrelation in univariate linear modeling of FMRI data, NeuroImage 14 (6) (2001) 1370-1386, https://doi.org/10.1006/nimg.2001.0931.

[28] M.W. Woolrich, T.E. Behrens, C.F. Beckmann, M. Jenkinson, S.M. Smith, Multilevel linear modelling for FMRI group analysis using Bayesian inference, NeuroImage 21 (4) (2004) 1732-1747, https://doi.org/10.1016/j.neuroimage.2003.12.023.

[29] M.W. Woolrich, T.E. Behrens, S.M. Smith, Constrained linear basis sets for HRF modelling using variational Bayes, NeuroImage 21 (4) (2004) 1748-1761, https:// doi.org/10.1016/j.neuroimage.2003.12.024.

[30] K.A. Johnson, N.C. Fox, R.A. Sperling, W.E. Klunk, Brain imaging in Alzheimer disease, Cold Spring Harb. Perspect. Med. 2 (4) (2012) a006213, https://doi.org/ 10.1101/cshperspect.a006213.

[31] N. Nellessen, C. Rottschy, S. Eickhoff, S. Ketteler, H. Kuhn, J. Shah, M. Schulz, K. Reske, Reetz, Specific and disease stage-dependent episodic memory-related brain activation patterns in Alzheimer's disease: a coordinate-based meta-analysis, Brain Struct. Funct. 220 (2014) 1555-1571, https://doi.org/10.1007/s00429-0140744-6.

[32] J.Y. Zhong, S.D. Moffat, Age-related differences in associative learning of landmarks and heading directions in a virtual navigation task, Front. Aging Neurosci. 8 (2016) 1-11, https://doi.org/10.3389/fnagi.2016.00122.

[33] P. Chen, Patterns of cognitive decline in presymptomatic Alzheimer disease, Arch. Gen. Psychiatry 58 (9) (2001) 853, https://doi.org/10.1001/archpsyc.58.9.853.

[34] M.H. Tabert, J.J. Manly, X. Liu, G.H. Pelton, S. Rosenblum, M. Jacobs, D. Zamora, M. Goodkind, K. Bell, Y. Stern, D.P. Devanand, Neuropsychological prediction of conversion to Alzheimer disease in patients with mild cognitive impairment, Arch. Gen. Psychiatry 63 (8) (2006) 916, https://doi.org/10.1001/archpsyc.63.8.916.

[35] C. Ballard, S. Gauthier, A. Corbett, C. Brayne, D. Aarsland, E. Jones, Alzheimer's disease, Lancet 377 (9770) (2011) 1019-1031, https://doi.org/10.1016/s01406736(10)61349-9.

[36] S. Sevush, N. Leve, Denial of memory deficit in Alzheimer's disease, Am. J. Psychiatry 150 (5) (1993) 748-751, https://doi.org/10.1176/ajp.150.5.748.

[37] S. Chapman, L.E. Colvin, M. Vuorre, G. Cocchini, J. Metcalfe, E.D. Huey, S. Cosentino, Cross domain self-monitoring in anosognosia for memory loss in Alzheimer's disease, Cortex 101 (2018) 221-233, https://doi.org/10.1016/j.cortex. 2018.01.019.

[38] A. Perrotin, B. Desgranges, B. Landeau, F. Mézenge, R. La Joie, S. Egret, A. Pélerin, V. de la Sayette, F. Eustache, G. Chételat, Anosognosia in Alzheimer disease: disconnection between memory and self-related brain networks, Ann. Neurol. 78 (3) (2015) 477-486, https://doi.org/10.1002/ana.24462.

[39] R.S. Rosenbaum, M. Ziegler, G. Winocur, C.L. Grady, M. Moscovitch, "I have often walked down this street before": fMRI studies on the hippocampus and other structures during mental navigation of an old environment, Hippocampus 14 (7) (2004) 826-835, https://doi.org/10.1002/hipo.10218.

[40] M. Hirshhorn, C. Grady, R. Rosenbaum, G. Winocur, M. Moscovitch, The hippocampus is involved in mental navigation for a recently learned, but not a highly familiar environment: a longitudinal fMRI study, Hippocampus 22 (4) (2012) 842-852, https://doi.org/10.1002/hipo.20944. 
[41] J. Wegman, A. Tyborowska, G. Janzen, Encoding and retrieval of landmark-related spatial cues during navigation: an fMRI study, Hippocampus 24 (7) (2014) 853-868, https://doi.org/10.1002/hipo.22275.

[42] R.G. Benoit, D.L. Schacter, Specifying the core network supporting episodic simulation and episodic memory by activation likelihood estimation, Neuropsychologia 75 (2015) 450-457, https://doi.org/10.1016/j.neuropsychologia.2015.06.034.

[43] B.A. Kirchhoff, A.D. Wagner, A. Maril, C.E. Stern, Prefrontal-temporal circuitry for episodic encoding and subsequent memory, J. Neurosci. 20 (16) (2000) 6173-6180, https://doi.org/10.1523/JNEUROSCI.20-16-06173.2000.

[44] C.I. Winlove, F. Milton, J. Ranson, J. Fulford, M. MacKisack, F. Macpherson, A. Zeman, The neural correlates of visual imagery: a co-ordinate-based meta-analysis, Cortex 105 (2018) 4-25, https://doi.org/10.1016/j.cortex.2017.12.014.

[45] M. Kilintari, S. Narayana, A. Babajani-Feremi, R. Rezaie, A.C. Papanicolaou, Brain activation profiles during kinesthetic and visual imagery: an fMRI study, Brain Res. 1646 (2016) 249-261, https://doi.org/10.1016/j.brainres.2016.06.009.

[46] K. Doya, Complementary roles of basal ganglia and cerebellum in learning and motor control, Curr. Opin. Neurobiol. 10 (6) (2000) 732-739, https://doi.org/10. 1016/S0959-4388(00)00153-7.

[47] M. Kawato, Internal models for motor control and trajectory planning, Curr. Opin. Neurobiol. 9 (6) (1999) 718-727, https://doi.org/10.1016/S0959-4388(99) 00028-8.

[48] T. Hanakawa, M.A. Dimyan, M. Hallett, Motor planning, imagery, and execution in the distributed motor network: a time-course study with functional MRI, Cereb. Cortex 18 (12) (2008) 2775-2788, https://doi.org/10.1093/cercor/bhn036.

[49] M.E. Raichle, A.M. MacLeod, A.Z. Snyder, W.J. Powers, D.A. Gusnard, G.L. Shulman, A default mode of brain function, Proc. Natl. Acad. Sci. U. S. A. 98 (2) (2001) 676-682, https://doi.org/10.1073/pnas.98.2.676.

[50] M.E. Raichle, The brain's default mode network, Annu. Rev. Neurosci. 38 (1) (2015) 433-447, https://doi.org/10.1146/annurev-neuro-071013-014030.

[51] E.L. Dennis, P.M. Thompson, Functional brain connectivity using fMRI in aging and Alzheimer's disease, Neuropsychol. Rev. 24 (1) (2014) 49-62, https://doi.org/10. 1007/s11065-014-9249-6.

[52] A.M. Fjell, L. McEvoy, D. Holland, A.M. Dale, K.B. Walhovd, Alzheimer's disease neuroimaging initiative, what is normal in normal aging? Effects of aging, amyloid and Alzheimer's disease on the cerebral cortex and the hippocampus, Prog. Neurobiol. (2014), https://doi.org/10.1016/j.pneurobio.2014.02.004.

[53] C. Hohenfeld, C.J. Werner, K. Reetz, Resting-state connectivity in neurodegenerative disorders: is there potential for an imaging biomarker? NeuroImage 18 (2018) 849-870, https://doi.org/10.1016/j.nicl.2018.03.013.

[54] S.D. Moffat, W. Elkins, S.M. Resnick, Age differences in the neural systems sup porting human allocentric spatial navigation, Neurobiol. Aging 27 (7) (2006) 965-972, https://doi.org/10.1016/j.neurobiolaging.2005.05.011.

[55] R. Cabeza, N.D. Anderson, J.K. Locantore, A.R. McIntosh, Aging gracefully: compensatory brain activity in high-performing older adults, NeuroImage 17 (3) (2002)
1394-1402, https://doi.org/10.1006/nimg.2002.1280.

[56] S. Belleville, L. Bherer, Biomarkers of cognitive training effects in aging, Curr. Transl. Geriatr. Exp. Gerontol. Rep. 1 (2) (2012) 104-110, https://doi.org/10. 1007/s13670-012-0014-5.

[57] A. Mechelli, G.W. Humphreys, K. Mayall, A. Olson, C.J. Price, Differential effects of word length and visual contrast in the fusiform and lingual gyri during, Proc. R. Soci. Lond. Ser. B: Biol. Sci. 267 (1455) (2000) 1909-1913, https://doi.org/10. 1098/rspb.2000.1229.

[58] L. Zhang, L. Qiao, Q. Chen, W. Yang, M. Xu, X. Yao, J. Qiu, D. Yang, Gray matter volume of the lingual gyrus mediates the relationship between inhibition function and divergent thinking, Front. Psychol. 7 (2016) 1-10, https://doi.org/10.3389/ fpsyg.2016.01532.

[59] M. Olivetti Belardinelli, M. Palmiero, C. Sestieri, D. Nardo, R. Di Matteo, A. Londei, A. D'Ausilio, A. Ferretti, C. Del Gratta, G. Romani, An fMRI investigation on image generation in different sensory modalities: the influence of vividness, Acta Psychol. 132 (2) (2009) 190-200, https://doi.org/10.1016/j.actpsy.2009.06.009.

[60] A.M. Kueider, J.M. Parisi, A.L. Gross, G.W. Rebok, Computerized cognitive training with older adults: a systematic review, PLoS ONE 7 (7) (2012) e40588, https://doi. org/10.1371/journal.pone.0040588.

[61] L. Clare, R.T. Woods, Cognitive training and cognitive rehabilitation for people with early-stage Alzheimer's disease: a review, Neuropsychol. Rehabil. 14 (4) (2004) 385-401, https://doi.org/10.1080/09602010443000074.

[62] M. Kivipelto, F. Mangialasche, T. Ngandu, Lifestyle interventions to prevent cognitive impairment, dementia and Alzheimer disease, Nat. Rev. Neurol. 14 (11) (2018) 653-666, https://doi.org/10.1038/s41582-018-0070-3.

[63] A. Robins, Transfer in cognition, Connect. Sci. 8 (2) (1996) 185-204, https://doi. org $/ 10.1080 / 095400996116875$.

[64] H. Noack, M. Lövdén, F. Schmiedek, On the validity and generality of transfer effects in cognitive training research, Psychol. Res. 78 (6) (2014) 773-789, https:// doi.org/10.1007/s00426-014-0564-6.

[65] Y. Stern, Cognitive reserve, Neuropsychologia 47 (10) (2009) 2015-2028, https:// doi.org/10.1016/j.neuropsychologia.2009.03.004.

[66] K. Amano, K. Shibata, M. Kawato, Y. Sasaki, T. Watanabe, Learning to associate orientation with color in early visual areas by associative decoded fMRI neurofeedback, Curr. Biol. 26 (14) (2016) 1861-1866, https://doi.org/10.1016/j.cub. 2016.05.014.

[67] M. Ramot, S. Kimmich, J. Gonzalez-Castillo, V. Roopchansingh, H. Popal, E. White, S.J. Gotts, A. Martin, Direct modulation of aberrant brain network connectivity through real-time NeuroFeedback, eLife 6 (2017) 1-23, https://doi.org/10.7554/ eLife.28974.

[68] M. Rance, C. Walsh, D.G. Sukhodolsky, B. Pittman, M. Qiu, S.A. Kichuk, S. Wasylink, W.N. Koller, M. Bloch, P. Gruner, D. Scheinost, C. Pittenger, M. Hampson, Time course of clinical change following neurofeedback, Neurolmage 181 (March) (2018) 807-813, https://doi.org/10.1016/j.neuroimage.2018.05.001. 